\title{
Health effects of solvent exposure among dockyard painters: mortality and neuropsychological symptoms
}

\author{
Ruoling Chen, Finlay Dick, Anthony Seaton
}

\begin{abstract}
Objectives-To study mortality and prevalence of neuropsychological symptoms among a cohort of painters known to have been heavily exposed to organic solvents.

Methods-A mortality study of 1292 male painters who had worked in a dockyard in Scotland for $\geqslant 1$ year between 1950 and 1992 comprised a nested cross sectional study of 953 surviving painters from the cohort and 953 male non-painters randomly selected from the local population and a case-control study of those with high symptom scores. Mortality, symptoms, and risks associated with painting, adjusting for age, education, smoking, alcohol, and personality were measured.

Results-The proportional mortality ratio for all cancers was not increased significantly (110 (95\% confidence interval $(95 \%$ CI) 84 to 143), except for a possible excess of deaths from ischaemic heart disease (132, 105 to 164$)$. Standardised mortality ratios were not signficantly increased. Among the 260 surviving painters and 539 community controls who responded to the questionnaire there was a significant excess of symptoms among painters; adjusted relative risk (RR) increased significantly with increasing symptom score. These RRs suggested an exposureresponse relation; for a high score (12-22) for all symptoms RR was 2.27 (1.20 to 4.30) for 1-4 years of exposure, 2.42 (1.18 to 4.95) for 5-9 years, 2.89 (1.42 to 5.88) for 10-14 years, and 3.41 (1.82 to 6.36) for 15-41 years, compared with controls. In multivariate analyses, painting exposure, and aging were associated with high symptom scores and there was again an increased risk relative to time worked as a painter.

Conclusion-This study supports the hypothesis that heavy and prolonged exposure to paint solvents leads to neuropsychological ill health.

(Occup Environ Med 1999;56:383-387)
\end{abstract}

Keywords: solvents; painters; neuropsychology

Many people are exposed to organic solvents and concerns about effects on neuropsychological health and on other internal organs have been raised..$^{1-7}$ Nevertheless, scepticism has been expressed that solvents entail a serious risk nowadays. ${ }^{89}$ In particular, some studies have suggested chronic neurotoxic effects in painters, ${ }^{12} 1011$ whereas others have not. ${ }^{12}{ }^{13} \mathrm{We}$ therefore carried out both a cohort mortality and a nested cross sectional questionnaire study of painters heavily exposed to organic solvents in a United Kingdom dockyard.

\section{Methods}

The study was approved by the local ethics committee, the employer, workforce representatives, and the local general practitioners. The cohort for the mortality study comprised all 1292 men who had worked in the paintshop at the dockyard for $\geqslant 12$ months between 1950 and 1992, and was followed up from 1 January 1960 to 31 December 1994. The target population for the questionnaire study was 953 painters from the mortality cohort who were not identified as dead at the end of 1995, together with 953 age matched male controls, randomly sampled from the current lists of the general practitioners of the local town. The vital status of cohort members was identified and copies of the death certificates were provided by the General Register Office for Scotland. Both proportional mortality ratios (PMRs) within the cohort and standardised mortality ratios (SMRs) for comparison with the male population of Scotland were calculated.

The questionnaire was posted to subjects inviting them to participate in a study on the health of workers in the region, without mentioning the specific interest in dockyard painting. It was designed to obtain personal details, educational level, smoking, and alcohol consumption, symptoms of psychological and neurological disorders, ${ }^{14}$ and employment history. To check on comparability of the cases and controls, we measured aspects of personality on Eysenck's social conformity (L) scale, ${ }^{15}$ as this would have been expected to remain stable with or without exposure to solvents. Questions 1-16 (Q1-16), summarised as psychological symptoms, were derived from the Q-16 questionnaire used for screening in Nordic countries for the solvent syndrome, ${ }^{14}$ whereas questions $15-22$ (Q15-22) may be summarised as neurological. Questions 15 and 16 are common to both. We posted the questionnaire to non-responders three times at 4-week intervals.

Underlying causes of death were coded according to the 9th international code of diseases (ICD-9). For different causes of death PMRs were analysed first. For a subcohort of those painters born between 1900 and 1929, SMRs were analysed by a person-years at risk SMR program. ${ }^{16}$ Their significance was tested 
Table 1 Observed and expected deaths and PMRs and SMRs of painters

\begin{tabular}{|c|c|c|c|c|}
\hline \multirow[b]{2}{*}{ Cause of death (ICD-9) } & \multicolumn{2}{|l|}{ PMR cohort } & \multicolumn{2}{|c|}{ SMR subcohort * } \\
\hline & $O b s / E x p$ & $P M R(95 \% C I)$ & $O b s / E x p$ & $S M R(95 \% C I)$ \\
\hline All causes & 205 & & $123(125.05)$ & $98(82$ to 117$)$ \\
\hline All sites of cancer (140-208) & $58(52.58)$ & $110(84$ to 143$)$ & $42(34.47)$ & $122(88$ to 165$)$ \\
\hline Oesophagus (150) & $2(2.36)$ & $87(10$ to 306$)$ & $1(1.54)$ & $65(1.6$ to 362$)$ \\
\hline Stomach (151) & $5(4.20)$ & 119 (39 to 278$)$ & $3(2.59)$ & $116(24$ to 339$)$ \\
\hline Colon (153) & $4(3.33)$ & $120(33$ to 308$)$ & $3(2.18)$ & $138(28$ to 402$)$ \\
\hline Rectum (154) & $3(2.11)$ & $142(29$ to 416 & $2(1.37)$ & $146(18$ to 527$)$ \\
\hline Lung (162) & $23(21.26)$ & $108(69$ to 162$)$ & $16(14.29)$ & $112(64$ to 182$)$ \\
\hline Prostate $(185)$ & $6(2.67)$ & 225 (83 to 489$)$ & $6(2.28)$ & 263 (97 to 573 ) \\
\hline Bladder (188) & $4(1.83)$ & $219(60$ to 560$)$ & $4(1.31)$ & 305 (83 to 782$)$ \\
\hline Lymphosarcoma and reticulosarcoma (200) & $2(0.26)$ & 769 (93 to 2780 ) & $1(0.09)$ & $1110(28$ to 6190$)$ \\
\hline \multicolumn{5}{|l|}{ Hereditary and degenerative diseases of the central } \\
\hline nervous system $(330-337)$ & $3(1.36)$ & $221(46$ to 645$)$ & $2(0.78)$ & $256(31$ to 926$)$ \\
\hline Anterior horn cell disease (335) & $2(0.41)$ & $488(59$ to 1760$)$ & $1(0.23)$ & $435(11$ to 2420$)$ \\
\hline Diseases of the circulatory system $(390-459)$ & $105(98.66)$ & $106(87$ to 129$)$ & $63(64.40)$ & $98(75$ to 125$)$ \\
\hline Ischaemic heart disease $(410-414)$ & $82(62.04)$ & $132(105$ to 164$)$ & $49(44.44)$ & $110(82$ to 146$)$ \\
\hline Cerebrovascular disease (430-438) & $12(17.99)$ & $67(35$ to 117$)$ & $9(12.30)$ & $73(34$ to 139$)$ \\
\hline Diseases of the respiratory system $(460-519)$ & $19(18.72)$ & 101 (61 to 158$)$ & $11(13.02)$ & $85(42$ to 151$)$ \\
\hline Chronic bronchitis (491) & $6(4.91)$ & $122(45$ to 266$)$ & $3(2.42)$ & $124(26$ to 362$)$ \\
\hline Emphysema (492) & $2(0.47)$ & $426(52$ to 1540$)$ & $2(0.35)$ & $571(69$ to 2060$)$ \\
\hline External causes of injury and poisoning (E800-999) & $10(12.55)$ & $80(38$ to 147$)$ & $2(3.63)$ & $55(6.7$ to 199$)$ \\
\hline Unknown & 5 & & & \\
\hline
\end{tabular}

^309 Painters, born between 1900 and 1929, a 20 year follow up from 1 January 1975 to 31 December 1994 and contributed 3690 person-years at risk.

and $95 \%$ confidence intervals (95\% CIs) calculated assuming a Poisson distribution. ${ }^{17}$ For the cross sectional study, the differences in characteristics of subjects and scores for neuropsychological symptoms between painters and non-exposed controls were examined by $\chi^{2}$ tests. A Breslow-Cox model ${ }^{18}$ was used to estimate the effects after controlling for the potential confounders age, educational level, smoking, alcohol intake, and social conformity, whereas a logistical regression model was used for the case-control study. Smoking was included as a categorical variable (nonsmokers, ex-smokers, and current smokers) and alcohol as a continuous variable (average units/week). Exposure data were included as years worked as a dockyard painter and time elapsed after leaving the dockyard. Social conformity (or dissimulation) was included as a score of $\leqslant 12$ on the L part of the Eysenck N/L personality inventory. Results are expressed as relative risks (RRs) relative to the prevalence in controls.

\section{Results}

MORTALITY STUDY

At the end of follow up, 205 painters were dead, 989 were alive, and 98 were of unknown vital status. Table 1 shows the pattern of mortality among the painters. For PMR, the only suggestion of an increase in risk of death was from ischaemic heart disease. The SMR showed no significant excess mortality.

CROSS SECTIONAL STUDY

In all, 875 subjects returned completed questionnaires (302 painters, 573 controls). The rate of completing the questionnaires by those who received them (excluding those with serious illness-five painters and nine controls-or untraceable addresses-325 painters and 20 controls) was $48.5 \%$ for painters and $62.0 \%$ for controls, the overall response rate being $56.6 \%$. After exclusion of painters from the control group and non-painters from the painter group, 260 painters and 539 non-exposed controls were included in the analyses.

Table 2 Neuropsychological symptoms among painters compared with controls

\begin{tabular}{|c|c|c|c|c|}
\hline Questions and symptoms & $\begin{array}{l}\text { Painters/ } \\
\text { controls }\end{array}$ & $P R R^{\star *}$ & $95 \% C I$ & $\chi^{2}$ test $p$ value \\
\hline Do you have a short memory? & $102 / 150$ & 1.42 & 1.15 to 1.73 & 0.001 \\
\hline Have you ever been told that you have a short memory? & $84 / 138$ & 1.27 & 1.01 to 1.58 & 0.044 \\
\hline Do you often have to make notes about what you must remember? & $98 / 231$ & 0.88 & 0.73 to 1.06 & 0.177 \\
\hline $\begin{array}{l}\text { Do you often have to go back to check things that you have done, such as turned off the stove, } \\
\text { locked the door, etc? }\end{array}$ & $138 / 227$ & 1.27 & 1.09 to 1.47 & 0.003 \\
\hline Do you generally find it hard to get the meaning from reading the newspaper and books? & $35 / 47$ & 1.55 & 1.03 to 2.34 & 0.037 \\
\hline Do you often have problems with concentrating? & $89 / 131$ & 1.41 & 1.13 to 1.77 & 0.003 \\
\hline Do you often feel irritated without any particular reason? & $97 / 168$ & 1.20 & 0.98 to 1.47 & 0.078 \\
\hline Do you often feel depressed for no particular reason? & $77 / 116$ & 1.38 & 1.08 to 1.77 & 0.011 \\
\hline Are you abnormally tired? & $72 / 99$ & 1.51 & 1.16 to 1.97 & 0.002 \\
\hline Are you less interested in sex than you think is normal? & $73 / 114$ & 1.33 & 1.03 to 1.72 & 0.028 \\
\hline Do you have palpitations of the heart even when you don't exert yourself? & $52 / 71$ & 1.52 & 1.10 to 2.11 & 0.011 \\
\hline Do you sometimes feel a pressure in your chest? & $86 / 122$ & 1.47 & 1.16 to 1.85 & 0.001 \\
\hline Do you perspire without any particular reason? & $70 / 90$ & 1.62 & 1.23 to 2.13 & 0.001 \\
\hline Do you have a headache at least once a week? & $75 / 115$ & 1.36 & 1.06 to 1.74 & 0.018 \\
\hline Do you often have a painful tingling in some part of your body? & $87 / 107$ & 1.69 & 1.33 to 2.15 & 0.0000 \\
\hline Do you have any problems buttoning and unbuttoning? & $31 / 22$ & 2.93 & 1.73 to 4.96 & 0.0000 \\
\hline Do you have bouts of dizziness? & $53 / 60$ & 1.84 & 1.31 to 2.58 & 0.0004 \\
\hline Do your hands tremble? & $50 / 47$ & 2.21 & 1.53 to 3.20 & 0.0000 \\
\hline Do you bump into people or things when moving around? & $25 / 30$ & 1.73 & 1.04 to 2.89 & 0.033 \\
\hline Do you feel weak or unsteady in your arms or legs? & $64 / 63$ & 2.11 & 1.54 to 2.90 & 0.0000 \\
\hline Do you find that you can't quite remember things although they are "on the tip of your tongue"? & $151 / 286$ & 1.10 & 0.96 to 1.25 & 0.164 \\
\hline Do you have difficulty falling asleep? & $96 / 128$ & 1.56 & 1.25 to 1.94 & 0.0001 \\
\hline
\end{tabular}

${ }^{\star}$ Numbers of Yes answers with from painters and controls, based on 260 painters and 539 controls. 
Table 3 Scores for neuropsychological symptoms by years of painting and relative risks for all painters

\begin{tabular}{|c|c|c|c|c|c|c|c|}
\hline \multirow[b]{3}{*}{ Scores } & \multirow[b]{2}{*}{ Controls } & \multirow[b]{3}{*}{$95 \% C I$} & \multicolumn{4}{|c|}{ Years as painters } & \multirow[b]{3}{*}{ Total } \\
\hline & & & $1-4$ & $5-9$ & $10-14$ & $15-41$ & \\
\hline & $R R$ & & $R R^{*}$ & $95 \% C I$ & & & \\
\hline $0-1$ & 0.72 & $\begin{array}{l}135 \\
0.54 \text { to } 0.97\end{array}$ & $\begin{array}{l}22 \\
0.71\end{array}$ & $\begin{array}{l}8 \\
0.50 \text { to } 1.00\end{array}$ & 7 & 10 & 47 \\
\hline $2-4$ & 0.77 & $\begin{array}{l}166 \\
0.60 \text { to } 1.00\end{array}$ & $\begin{array}{l}22 \\
0.80\end{array}$ & $\begin{array}{l}15 \\
0.59 \text { to } 1.08\end{array}$ & 9 & 16 & 62 \\
\hline $5-7$ & 0.88 & $\begin{array}{l}122 \\
0.66 \text { to } 1.18\end{array}$ & $\begin{array}{l}13 \\
0.89\end{array}$ & $\begin{array}{l}16 \\
0.64 \text { to } 1.25\end{array}$ & 13 & 10 & 52 \\
\hline $8-11$ & 1.30 & $\begin{array}{l}80 \\
0.94 \text { to } 1.79\end{array}$ & $\begin{array}{l}19 \\
1.27\end{array}$ & $\begin{array}{l}11 \\
0.88 \text { to } 1.84\end{array}$ & 10 & 10 & 50 \\
\hline $12-22$ & 2.82 & $\begin{array}{l}36 \\
1.88 \text { to } 4.23\end{array}$ & $\begin{array}{l}14 \\
2.71\end{array}$ & $\begin{array}{l}10 \\
1.73 \text { to } 4.24\end{array}$ & 10 & 15 & 49 \\
\hline Total & & 539 & 90 & 60 & 49 & 61 & 260 \\
\hline
\end{tabular}

Number of painters by years of exposure are in italics.

*Adjusted for age, educational level, smoking, alcohol intake, and social conformity.

The prevalence rate ratios (or RRs) for individual neuropsychological symptoms were significantly higher among painters for every question except three, the highest risks being for the neurological symptoms, problems buttoning and unbuttoning, hands trembling, and for feeling weak or unsteady in the arms or legs (table 2). A total score of all symptoms, summarised from Q1-22, was calculated for painters and controls (table 3). The distribution of the scores was skewed with a mode of one symptom. The RRs and the adjusted RRs for painters with symptoms increased significantly with increasing scores (trend, $\mathrm{p}<0.00001)$. In separate analyses of the scores of psychological and neurological symptoms, both distributions showed similar trends to that of all combined (table 4). The painters had an increased risk of high scores, compared with controls, for both psychological and neurological symptoms; both trends were significant at $\mathrm{p}<0.00001$.

For painters with a score of $\geqslant 12$ for all neuropsychological symptoms, the RRs (95\% CIs) increased significantly with years of exposure to painting: 2.32 (1.31 to 4.14 ) for $1-4$ years of exposure, 2.50 (1.31 to 4.77 ) for 5-9 years, 3.06 (1.62 to 5.78 ) for $10-14$ years, and 3.68 (2.14 to 6.32 ) for $15-41$ years (trend $\mathrm{p}<0.00001$ ), suggesting an exposure-response relation. This was not apparent for scores $<12$. After adjustment for confounding factors, this relation remained, the RRs for painters with a score of 12-22 for all symptoms being 2.27 (1.20 to 4.30 ) for $1-4$ years of exposure, 2.42 (1.18 to 4.94 ) for 5-9 years, 2.89 (1.42 to 5.88 ) for $10-14$ years, and 3.41 (1.81 to 6.36) for 15-41. The effect of time since stopping painting on all symptoms was also examined. For scores of $12-22$, the RRs were 2.76 (1.51 to 5.04) for active painters, 3.02 (1.86 to 4.89 ) for those within 1-10 years of stopping, 2.50 (1.13 to 5.53) for those who had not worked for 11-18 years, and 2.66 (1.32 to 5.38 ) for those who had not worked for $>19$ years. In analyses adjusted for age, educational level, smoking, alcohol intake, social conformity, and years of painting exposure, the results also showed no significant decrease in risk with time: 3.71 (1.66 to 8.29), 3.53 (1.79 to 6.96), 2.72 (1.03 to 7.19 ), and 2.98 (1.06 to 8.35 ), respectively.

As a score $\geqslant 12$ for all symptoms had the highest risk and showed a significant exposureresponse relation, we considered these subjects to be cases and those with a score 0 or 1 as controls for a nested case-control analysis (table 3; 96 painters and 171 non-painters were included). The multivariate analysis still showed evidence of an exposure-response relation. The odds ratios (ORs) increased with years of exposure to painting: 2.82 (1.09 to 7.33) for 1-4 years of exposure, 6.08 (1.72 to 21.46) for 5-9 years, 6.95 ( 2.03 to 23.86 ) for 10-14 years and 6.14 (2.02 to 18.67) for 15-41 years. Also, the ORs increased with age (OR for 70-96 years old being 7.80, 1.02 to 59.59).

Table 4 Relative risks of psychological and neurological symptoms in painters $v$ controls

\begin{tabular}{|c|c|c|c|c|c|c|c|}
\hline \multirow[b]{2}{*}{ Symptom score } & \multicolumn{3}{|l|}{ Subjects } & \multirow[b]{2}{*}{$R R$} & \multirow[b]{2}{*}{$95 \% C I$} & \multirow[b]{2}{*}{$R R^{\star}$} & \multirow[b]{2}{*}{$95 \% C I^{\star}$} \\
\hline & Controls & Painters & Total & & & & \\
\hline \multicolumn{8}{|l|}{ Psychological: } \\
\hline 0 & 83 & 32 & 115 & 0.80 & 0.55 to 1.17 & 0.77 & 0.50 to 1.17 \\
\hline $1-2$ & 159 & 58 & 217 & 0.76 & 0.58 to 0.98 & 0.75 & 0.55 to 1.03 \\
\hline $3-4$ & 118 & 47 & 165 & 0.83 & 0.61 to 1.12 & 0.87 & 0.61 to 1.23 \\
\hline $5-8$ & 128 & 72 & 200 & 1.17 & 0.91 to 1.49 & 1.16 & 0.86 to 1.57 \\
\hline $9-12$ & 41 & 36 & 77 & 1.82 & 1.19 to 2.78 & 1.85 & 1.16 to 2.96 \\
\hline $13-16$ & 10 & 15 & 25 & 3.11 & 1.42 to 6.83 & 2.76 & 1.21 to 6.27 \\
\hline Total & 539 & 260 & 799 & & & & \\
\hline \multicolumn{8}{|l|}{ Neurological: } \\
\hline 0 & 160 & 61 & 221 & 0.79 & 0.61 to 1.02 & 0.80 & 0.59 to 1.09 \\
\hline 1 & 194 & 57 & 251 & 0.61 & 0.47 to 0.79 & 0.64 & 0.47 to 0.87 \\
\hline 2 & 98 & 54 & 152 & 1.14 & 0.85 to 1.54 & 1.14 & 0.81 to 1.61 \\
\hline 3 & 40 & 28 & 68 & 1.15 & 0.92 to 2.30 & 1.31 & 0.80 to 2.16 \\
\hline 4 & 22 & 22 & 44 & 2.07 & 1.17 to 3.67 & 1.82 & 0.99 to 3.36 \\
\hline 5 & 13 & 15 & 28 & 2.39 & 1.16 to 4.95 & 2.25 & 1.04 to 4.88 \\
\hline $6-8$ & 12 & 23 & 35 & 3.97 & 2.01 to 7.86 & 3.84 & 1.86 to 7.94 \\
\hline Total & 539 & 260 & 799 & & & & \\
\hline
\end{tabular}

^Adjustment for age, educational level, smoking, alcohol weekly units, and social conformity. 
Table 5 Case-control multivariate analysis of all neuropsychological symptoms: subjects with high scores $v$ those with low scores

\begin{tabular}{lll}
\hline Factors & OR & 95\% CI \\
\hline Age (y): & & \\
19-29 & 1.00 & \\
$30-34$ & 0.64 & 0.11 to 3.85 \\
$35-39$ & 0.73 & 0.12 to 4.52 \\
$40-44$ & 1.19 & 0.22 to 6.50 \\
$45-49$ & 1.69 & 0.32 to 9.03 \\
$50-54$ & 1.17 & 0.20 to 6.79 \\
$55-59$ & 2.06 & 0.32 to 13.25 \\
$60-64$ & 2.15 & 0.37 to 12.55 \\
$65-69$ & 2.06 & 0.32 to 13.31 \\
$70-96$ & 7.80 & 1.02 to 59.59 \\
Education: & & \\
No training & 1.00 & \\
Apprenticeship & 1.03 & 0.43 to 2.50 \\
Technical college & 0.87 & 0.35 to 2.15 \\
University and above & 0.14 & 0.08 to 7.93 \\
Smoking: & & \\
Non-smoker & 1.00 & \\
Ex-smoker & 1.22 & 0.53 to 2.78 \\
Current smoker & 1.57 & 0.70 to 3.56 \\
Alcohol intake (average units/week): & & \\
$0-3.9$ & 1.00 & \\
$4.0-7.9$ & 0.83 & 0.20 to 3.44 \\
$8.0-13.9$ & 1.36 & 0.40 to 4.64 \\
$14.0-22.5$ & 0.95 & 0.27 to 3.33 \\
$22.6-99.0$ & 2.67 & 0.83 to 8.58 \\
Years of painting exposure at dockyard: & \\
0 & 1.00 & \\
$1-4$ & 2.82 & 1.09 to 7.33 \\
$5-9$ & 6.08 & 1.72 to 21.46 \\
$10-14$ & 6.95 & 2.03 to 23.86 \\
$15-41$ & 6.14 & 2.02 to 18.67 \\
Scores of social conformity: & & \\
$0-1.9$ & 1.00 & \\
$2-2.9$ & 1.66 & 0.27 to 10.25 \\
$3-3.9$ & 0.39 & 0.05 to 3.12 \\
$4-4.9$ & 0.66 & 0.10 to 4.18 \\
$5-5.9$ & 0.52 & 0.09 to 2.98 \\
$6-6.9$ & 0.30 & 0.05 to 1.96 \\
$7-7.9$ & 0.51 & 0.09 to 2.88 \\
$8-8.9$ & 0.18 & 0.03 to 1.17 \\
$9-9.9$ & 0.28 & 0.05 to 1.67 \\
$10-10.9$ & 0.45 & 0.07 to 3.02 \\
$11-12$ & & 0.00 to 0.23 \\
\hline & & \\
& &
\end{tabular}

The ORs for educational level, smoking, and alcohol intake were not significant, but the OR of the highest scores (11-12) of social conformity was 0.02 (0.00 to 0.23$)$.More detail is given in table 5 . Analyses of psychological symptoms (0-1 scores as controls, 9-16 as cases; 101 painters and 247 non-painters) and neurological symptoms (0 score as controls, 5-8 as cases; 63 painters and 221 non-painters) were performed separately, and showed similar patterns, significantly increased risks being associated with painting.

\section{Discussion}

This study has shown a risk of excess neuropsychological symptoms among dockyard painters over controls, on a background of no unexpected mortality patterns. The cohort size meant that small increases in risk of cancers or rare neurological disease would not have been detected, but it may be of interest that two of our cohort died of motor neuron disease in view of previous reports of an association between neurological disease and solvent exposure. ${ }^{19} 20$

The possibility that the neuropsychological symptoms were caused by exposure to substances at work is suggested by the exposureresponse relation, even though our estimates of exposure were crude, relying on years worked in the dockyard. We know that few safety precautions were taken to reduce exposure over most of the relevant period, and in our current research we are making more accurate assessments of exposure as part of a case-control study in which we are also measuring neuropsychological function. We attempted to allow for various biases and confounding factors to increase confidence in our findings. Response bias was avoided by concealing the precise objective of the investigation, participants being invited to take part in a study of general health in the locality in relation to work, no specific mention being made of painting. As is often the case, many subjects could not be contacted because of migration from the area, and others failed to respond despite repeated requests. This particularly applied to painters, many of whom will have left the area in the decades since the start of the cohort follow up, whereas the controls were all identified from current general practice lists. As such a response rate may have introduced bias in an undeterminable direction, we have been able to repeat this study in China where we obtained a better than $94 \%$ response rate and have found closely similar results. ${ }^{21}$ In that study of 109 dockyard painters and 255 controls, the RR for a neuropsychological score of 12-22 was 4.09 (95\% CI 2.73 to 6.15 ). Among the painters in the present study, the distributions of age among responders (mean 51.3 (SD 14.0)), non-responders (47.6 (13.0)), and uncontactable subjects (49.7 (12.5)) showed no significant differences.

The control subjects were contacted with the same methods as the painters, and the responders included a higher proportion of more educated people, a source of bias which we have allowed for in the analyses. It is possible that some subjects with brain damage might have found the questionnaire too difficult to complete; if indeed brain damage were an effect of solvent exposure, this would have tended to minimise differences found. Our confidence in the validity of our findings is increased by the presence of an exposureresponse relation, duration of painting experience being associated with increased risk of a high symptom score compared with the controls. Also, in this study we found no significant differences between painters and controls for the social conformity (L) scale of the Eysenck questionnaire. ${ }^{22}$ This measures the propensity to answer truthfully and provides some evidence of comparability of the groups. The confounding effects of age, alcohol consumption, and cigarette smoking were also allowed for in the analyses without changing the overall findings.

There is some consistency and coherence in the literature for neurotoxic effects of paint solvents. Axelson et al found, in a case-control study of disability pensioners in Sweden, ${ }^{10}$ that workers exposed to solvents had an RR of about 1.8 of having neuropsychiatric disorders compared with other skilled workers in various trades. Two studies from Denmark have shown that subjects exposed to solvent have an RR of about $2-3$ of developing dementia, ${ }^{23}{ }^{24}$ whereas several groups have found abnormal perform- 
ance on neuropsychological tests in workers exposed to solvents, ${ }^{125} 26$ and a recent community based study has suggested an association between exposure to organic solvents and Alzheimer's disease. ${ }^{27}$

By contrast with this, some studies have not shown a relation between exposure to solvents and evidence of neuropsychological disease. ${ }^{12}{ }^{13}{ }^{28-30}$ It is to be expected that there would be conflicting published results, as adverse effects of solvents are likely to be dosedependent, and many groups of workers are no longer exposed to high concentrations. In the dockyard, the solvents used were mainly white spirit, xylene, trimethylbenzene, n-butanol, trichlorethylene, naptha, and cumene. Toluene, butan-2-one, 4-methylhexan-2-one, methyl ethyl ketone, and 2-ethoxyethanol had been present in some paints, and dichloromethane was in use as a stripper. Some painters had also been exposed to lead, a well known neurotoxin, which may have contributed to the effects we have found. Measurements made in the yard have shown that solvent exposures were at times well above relevant exposure limits (OELs), especially in enclosed spaces. Reconstruction of some of these conditions in 1996 (unpublished data) has shown that personal exposures would at times have been significantly above the relevant OELs, both in spray painting and in internal compartments of vessels - for example, averaged concentration of xylene $<328 \mathrm{ppm}$, OEL $100 \mathrm{ppm}$, and methylethyl ketone $<723 \mathrm{ppm}$, OEL $200 \mathrm{ppm}$ ). There was potential for extensive dermal and respiratory exposure among our subjects, and reports of past episodes of narcosis have been recorded. ${ }^{3}$ In these circumstances, the finding of neuropsychological symptoms was perhaps not surprising. We anticipate that our current research will shed further light on the neuropsychological dysfunction we have found in these subjects.

Our results to date suggest that complacency about the safety of commonly used organic solvents is unjustified, ${ }^{31}$ and that heavy exposures in confined spaces may be associated with significantly increased risks of chronic neuropsychological disorder. A problem associated with the effects of such chemicals is that the patient may simply seem to be a little less intelligent or more emotionally disturbed than would otherwise be the case, and it is very easy for a doctor to dismiss such symptoms as a variant of normal or as an effect of age. The occupational history should alert one to the possibility of such symptoms being toxic in aetiology.

This research was supported by a fellowship for RC from the Colt Foundation, and formed part of his dissertation for a PhD at Aberdeen University. We thank Jill Seaton and Li Wei for their help in collecting and managing the data, and the GRO help in collecting and managing the data, and the GRO
Scotland, and the dockyard authorities, trade unions, and general practitioners for their support.
1 Baker EL. A review of recent research on health effects of human occupational exposure to organic solvents. $\mathcal{F}$ Occup human occupational exp $1994 ; 36: 1079-92$.

2 Hogstedt C. Has the Scandinavian solvent syndrome controversy been solved? Scand $\mathcal{f}$ Work Environ Health 1994;20:S59-64.

3 Seaton A, Jellinek EH, Kennedy P. Major neurological disease and occupational exposure to organic solvents. $Q \mathcal{F}$ Med 1992;84:707-12.

4 Tiller JR, Schilling RSF, Morris JM. Occupational toxic factors in mortality from coronary heart disease. BMF 1968;iv:407-11.

5 Wilcosky TC, Simonsen NR. Solvent exposure and cardiovascular disease. Am f Ind Med 1991;19:569-86.

6 Dossing M, Arlien-Söborg P, Petersen LM, et al. Liver damage associated with occupational exposure to organic solvents in house painters. Eur F Clin Invest 1983;13:151-7.

7 Yaqoob M, Bell GM, Stevenson A, et al. Renal impairment with chronic hydrocarbon exposure. $Q f$ Med 1993;86: 165-74.

8 Waldron HA. Solvents and the brain [editorial]. $\mathrm{Br} F$ Ind Med 1986;43:73-4.

9 Cranmer JM, Goldberg L. Human aspects of solvent neurobehavioral effects. Report of the workshop session on clinical and epidemiological topics. Neurotoxicology 1987;7: 43-56.

10 Axelson O, Hane M, Hogstedt C. A case-referent study on neuropsychiatric disorders among workers exposed to solvents. Scand $\mathcal{F}$ Work Environ Health 1976;2:14-20.

11 Wang JD, Chen JD. Acute and chronic neurological symptoms among paint workers exposed to mixtures of organic solvents. Environ Res 1993;61:107-16.

12 Triebig G. Occupational neurotoxicology of organic solvents and solvent mixtures. Neurotoxicol Teratol 1989;11:575-78.

13 Hooisma J, Hanninen $\mathrm{H}$, Emmen $\mathrm{HH}$, et al. Behavioral effects of exposure to organic solvents in Dutch painters. Neurotoxicol Teratol 1993;15:397-406.

14 Axelson O, Hogstedt C. On the health effects of solvents. In: Zenz C, ed. Occupational medicine: principles and practical Zenz C, ed. Occupational medicine: principles and practical applications, 2nd
Publishers; 1988.

15 Eysenck HJ. Dimensions of personality. London: Routledge and Kegan Paul, 1947

16 Chen R. An analysis program for occupational cohort mortality and update cancer risk in copper miners. Int $\mathcal{f}$ Occup Med Environ Health 1996;9:301-8.

17 Gardner MJ, Altman DG. Statistics with confidence. London: BMJ Publications, 1989.

18 Lee J. Odds ratio or relative risk for cross-sectional data? Int 7 Epidemiol 1994;23:201-3.

19 Graham AJ, Macdonald AM, Hawkes CH. British motor neurone disease twin study. F Neurol Neurosurg Psychiatry neurone disease twir

20 Welp E, Kogevinas M, Andersen A, et al. Exposure to styrene and mortality from nervous system diseases and mental disorders. Am F Epidemiol 1996;144:623-33.

21 Chen R, Wei L, Seaton A. Neuropsychological symptoms in Chinese male and female painters: an epidemiological study in dockyard workers. Occup Environ Med 1999;56:388-90.

22 Chen R. Health effects of solvent exposure: a study of dockyard painters [PhD Thesis]. Aberdeen: University of Aberdeen, 1997:81-4.

23 Olsen J, Sabroe S. A case-reference study of neuropsychiatric disorders among workers exposed to solvents in the ric disorders among workers exposed to solvents in the
Danish wood and furniture industry. Scand $\mathcal{f}$ Soc Med 1980;16:S44-9.

24 Mikkelsen S. A cohort study of disability pension and death among painters with special regard to disabling presenile dementia as an occupational disease. Scand $\mathcal{F}$ Soc Med 1980;16:S34-43.

25 Gregersen P, Angelso B, Nielsen TE, et al. Neurotoxic effects of organic solvents in exposed workers: an occupational, neuropsychological and neurological investigation. Am F Ind Med 1984;5:201-25.

26 Spurgeon A, Gray CN, Sims J, et al. Neurobehavioral effects of long-term occupational exposure to organic solventstwo comparable studies. Am f Ind Med 1992;22:325-35.

27 Kukull WA, Larson EB, Bowen JD, et al. Solvent exposure as a risk factor for Alzheimer's disease: a case-control study. A risk factor for Alzheimer's disease:

28 Maizlish NA, Langolf GD, Whitehead LW, et al. Behavioural evaluation of workers exposed to mixtures of organic solvents. Br f Ind Med 1985;42:579-90.

29 Fidler A, Bake EL, Letz RE. Neurobehavioral effects of occupational exposure to organic solvents among construction painters. Br F Ind Med 1987;44:292-308.

30 Hakkola $M$. Neuropsychological symptoms among tanker drivers with exposure to solvents. Occup Med 1994;44:2436.

31 Seaton A. Organic solvents and the nervous system: time for a reappraisal? [editorial]. $Q \mathcal{F} \mathrm{Med}$ 1992;84:637-9. 